\title{
A GESTALT-TERAPIA COMO CLÍNICA DO ENCONTRO: COMPREENDENDO A RELAÇÃO DIALÓGICA
}

\author{
Gestalt therapy as a clinic of engagement:Understanding the dialogical relation \\ La Gestalt-terapia como clínica de encuentro: Comprendiendo la relación dialógica
}

Hinayana Leão MotTa Gustavo Alves Pereira de Assis LeIla Ribeiro SATELIS

\begin{abstract}
Resumo: A gestalt-terapia constitui-se como uma psicoterapia dialógica, como uma clínica do encontro. Investigações empíricas sobre a interface existencialismo dialógico-psicoterapia gestáltica são escassas. Considerando a relação dialógica como eixo desta abordagem, objetivou-se compreender as experiências de profissionais de psicologia no tocante à relação dialógica em gestalt-terapia. Como recurso metodológico, utilizou-se a pesquisa qualitativa de método fenomenológico, de orientação semiótica. Foram realizadas entrevistas fenomenológicas abertas com cinco colaboradoras. Os dados foram gravados e transcritos na íntegra. A análise pautou-se na reflexibilidade fenomenológica, percorrendo pela descrição, redução e interpretação. Os resultados indicam a abertura, presença e o uso da epoché pelo terapeuta como elementos fundamentais para a relação dialógica. Experiências positivas de atitude Eu-Tu foram encontradas, sugerindo episódios culminantes deste processo. Houve confusão entre o conceito de atitude e momentos Eu-Tu, com valorização deste princípio em detrimento à atitude Eu-Isso, o que evidencia a necessidade de repensar a formação do gestalt-terapeuta. Assim, a relação dialógica em gestalt-terapia apresenta-se como um campo de pluralidades fenomênicas. Cabe ao profissional um andar cuidadoso e atento neste campo de inúmeras possibilidades.
\end{abstract}

Palavras-chave: Existencialismo; Método Fenomenológico; Psicoterapia; Relação Terapêutica.

Abstract:Gestalt therapy constitutes itself as a dialogical psychotherapy, a clinic of engagement.Empirical research on the dialogical existentialism-gestalt psychotherapy interface is scarce.Considering the dialogical relation as the axis of this approach, the objective was to understand the experiences of psychology professionals regarding the dialogical relation in gestalt therapy.As a methodological resource, we used the qualitative research of a phenomenological method, with a semiotic orientation.Open phenomenological interviews were carried out with five collaborators. The data were recorded and transcribed in full.The analysis was based on phenomenological reflexivity, through description, reduction, and interpretation.Results indicate the opening, presence, and use of epoché by the therapist as fundamental elements for the dialogical relation.Positive I-You attitude experiences have been found, suggesting culminating episodes of this process.There was confusion between the concept of I-You attitude and I-You moments, with an appreciation of this principle to the detriment of the I-It attitude, which evidences the need to rethink the formation of the gestalt therapist. Thus, the dialogical relation in gestalt therapy presents itself as a field of phenomenal pluralities.It is up to the professional to thread carefully and attentively in this field of innumerable possibilities.

Keywords: Existentialism; Phenomenological method; Psychotherapy;Therapeutic relation.

Resumen: La Gestalt-terapia se constituye como una psicoterapia dialógica, como una clínica del encuentro. Investigaciones empíricas sobre la interface existencialismo dialógico-psicoterapia gestáltica son raras. Considerando la relación dialógica como eje de este abordaje, se ha objetivado comprender las experiencias de profesionales de psicología con respecto a la relación dialógica en Gestalt-terapia. Como recurso metodológico se ha utilizado la investigación cualitativa de método fenomenológico, de orientación semiótica. Han sido realizadas entrevistas fenomenológicas abiertas con cinco colaboradoras. Los datos han sido grabados y transcritos en la íntegra. El análisis se ha pautado en la reflexividad fenomenológica, con un recorrido hacia la descripción, reducción e interpretación. Los resultados indican la apertura, presencia y el uso de la epojé por el terapeuta como elementos fundamentales para la relación dialógica. Experiencias positivas de actitud Yo-Tú han sido encontradas sugiriendo episodios culminantes de este proceso. Hubo confusión entre el concepto de actitud y momentos Yo-Tú, con la valorización de este principio en detrimento a la actitud Yo-Eso, lo que evidencia la necesidad de repensar la formación del Gestalt-terapeuta. Así, la relación dialógica en Gestalt-terapia se presenta como un campo de pluralidades fenoménicas. Cabe al profesional un andar cuidadoso y atento en este campo de innúmeras posibilidades.

Palabras-clave: Existencialismo; Método Fenomenológico; Psicoterapia; Relación Terapéutica. 


\section{Introdução}

A filosofia existencialista, de modo geral, colabora na constituição de um método analítico e reflexivo que permite a análise do existir humano (Ribeiro, 2012). No que se refere à perspectiva buberiana, esta elucida a existência como homem-com-o-homem, discutindo a dualidade da relação homem-confrontante, compreendendo a vida como relação (Zuben, 1979; Zuben, 2008). Trata-se, portanto, de uma ontologia da relação, de uma busca de apreensão da existência humana como fenômeno relacional.

O existencialismo dialógico de Martin Buber é uma filosofia do encontro, pois se inscreve na esfera do inter-humano. Essa perspectiva influenciou vários campos do saber, como a área da saúde. Se considerarmos a psicoterapia como uma prática em saúde, a teoria dialógica pode ser incorporada na praxe profissional (Zuben, 2003; Schaurich, Crossetti \& Padoin, 2011).

No âmbito da gestalt-terapia, os estudos buberianos constituem-se como um referencial para a base existencialista da abordagem, fundamentando-se como uma psicoterapia dialógica. Hycner (1995) afirma que a psicoterapia de base dialógica considera a totalidade do indivíduo, visando restaurar o relacional do homem, em um movimento de cura existencial genuína. Sendo assim, a gestalt-terapia institui-se como uma clínica da relação, do encontro, do entre.

A vida dialógica é compreendida como um movimento rítmico, como um processo de alternância. Na clínica gestáltica, a compreensão de relação terapêutica perpassa pelo entendimento do dialógico.Daí decorrem duas palavras-princípio: Eu-Isso e Eu-Tu. Buber (1923/2001) afirma categoricamente: "Não há $\mathrm{Eu}$ em si, mas apenas o Eu da palavra-princípio Eu-Tu e o Eu da palavra-princípio Eu-Isso” (p. 10). Essas palavras-princípios são atitudes, intencionalidades dinâmicas, formas de relação dual que constroem a existência humana enquanto ser-no-mundo. A atitude Eu-Isso envolve utilização, objetificação, experimentação, havendo coerência espaço-temporal e durabilidade. A atitude Eu-Tu envolve presença, reciprocidade, totalidade, imediatez. Portanto, temos dois mundos: o Mundo do Isso e o Mundo do Tu.O primeiro é o mundo da experimentação, e o segundo é o da relação (Buber, 1923/2001; Fernandes, 2007; Ramon, 2010; Zuben, 2003; Zuben, 2008).

As reflexões buberianas são de suma importância para a compreensão dos processos clínicos, ao considerar o psicoterapeuta como um profissional do encontro, como aponta Figueiredo (1993). Porém, torna-se fundamental uma leitura crítica sobre a articulação entre ciência psicológica e filosofia buberiana, identificando intersecções. Luczinki e Ancona-Lopez (2010) ponderam sobre esta problemática.

Como Buber é um filósofo, a transposição de seus conceitos para o campo dos fenômenos psíquicos exige reflexões críticas e comparações com as vivências na prática. Desta forma, torna-se importante repensar a relação eu-tu no âmbito da clínica e o papel do encontro no processo psicoterapêutico, dialogando com autores que empreenderam tais aproximações (p. 76).

Repensar a teoria de Buber no campo da psicoterapia gestáltica requer reflexões acadêmicas e estudos, pois, como afirmam Schaurich et al. (2011), a pesquisa científica colabora para reordenar práticas profissionais.Richard Hycner foi um dos autores que contribuíram para o movimento da psicoterapia dialógica, no que se refere ao caráter teórico, expressamente conhecido na comunidade gestáltica. Porém, em Joyce e Sills (2016) há uma preocupação com o que os autores chamam de "falta generalizada de interesse" em pesquisas empíricas na abordagem gestáltica, concluindo que esse fato se deve à aversão a metodologia científica muitas vezes correlacionadano imaginário aos estudos quantitativos. Os autores alegam que a gestalt-terapia pode contribuir significativamente para o campo da pesquisa, visto seu caráter reflexivo.

Gold e Zahm (2014) também apontam a escassez de estudos empíricos da abordagem gestáltica aplicada à psicoterapia, indicando possibilidades de temas a serem investigados. A qualidade do relacionamento terapêutico e a adesão aos princípios da relação dialógica são sugestões de questões a serem perscrutadas, pois a gestalt-terapia "tem muito a oferecer com pesquisas baseadas nas dinâmicas da relação psicoterapêutica” (p. 52). Sobre esse aspecto, Hycner e Jacobs (1997) afirmam que não há clareza no que vem a ser a relação terapêutica ou na sua natureza de difícil descrição, confirmando o que foi percebido.

Considerando este panorama, a problematização da pesquisa pauta-se na seguinte questão norteadora: Como são as experiências de psicólogas e psicólogos no que se refere à relação dialógica na clínica gestáltica? Deste modo, o objetivo foi compreender as experiências de profissionais de psicologia no tocante à relação dialógica em gestalt-terapia.

A pesquisa pauta-se na busca de elementos intersubjetivos da experiência de relação dialógica em gestalt-terapia. Isso significa que o estudo se deslindará na construção de uma estrutura fenomênica, que diz respeito às essências vivenciais fundamentais. Husserl (1907/1986) afirma que “(...) portanto, as investigações fenomenológicas são investigações universais de essências" (p.79). Refere-se, portanto, a uma busca pelas universalidades, pelas convergências nas percepções conscientes dos colaboradores. Essa perspectiva pauta-se na compreensão de que a essênciafenomênica é identificada como aquilo que é passível de ser tornado comum àexperiência humana, aquilo que é invariante (Andrade \& Holanda, 2010; Holanda, 2011; Husserl, 1907/1986). 


\section{Procedimentos metodológicos}

\section{Caracterização da Pesquisa}

A pesquisa é classificada como qualitativa, em sua abordagem, e fenomenológica de orientação semiótica, em seu método. A pesquisa qualitativa visa a compreensão de elementos que sejam significantes nos fenômenos, enfatizando a subjetividade, ao passo que a fenomenologia semiótica objetiva o estudo da experiência consciente dos indivíduose os signos subjacentes (Garnica, 1997; Gil, 2017; Gomes, 1997; Lanigan, 1997).

Para Amatuzzi (2009), a abordagem qualitativa de enfoque fenomenológico é usual nas linhas de pesquisa humanistas e existenciais, como a gestalt-terapia se inscreve. Deste modo, o delineamento propostomostra-se adequado para a investigação das experiências gestálticas no tocante à relação dialógica.

\section{Colaboradores}

A amostra desta pesquisa é constituída de cinco colaboradoras, com nomes fictícios escolhidos aleatoriamente. Os critérios de inclusão foram: ser psicóloga/psicólogo, ter formação ou especialização em gestalt-terapia e ter experiência clínica por um período mínimo de dois anos. A seguir, será apresentado o perfil das colaboradoras.

Sofia, Glória, Isabel, Júlia e Helena são gestalt-terapeutas, com idade entre quarenta e um e cinquenta e cinco anos. Todas possuem especialização em gestalt-terapia, com exceção de uma que possui formação, além de mestrado em psicologia. O tempo de prática clínica varia de cinco a trinta e dois anos. As colaboradoras residem em Goiânia e Rio Verde, municípios doestado de Goiás.

\section{Procedimentos}

O projeto foi submetido à apreciação ética e aprovado, sob o número do CAAE 74154317.5.0000.5077. Assim, a pesquisa pautou-se nos princípios éticos previstos nasResoluções do Conselho Nacional de Saúde (CNS) n 466/2012 e 510/2016, tais como confidencialidade, a ponderação sobre os riscos e benefícios, a anuência do participante após o esclarecimento dos objetivos e métodos da pesquisa, entre outros aspectos.

Realizou-se o recrutamento e seleção dos colaboradores mediante a técnica de bola de neve (snowball). Esse método de amostragem não-probabilística permite que,por meio de indicação da rede de contato dos autores, sejam captados possíveis colaboradores (Vinuto, 2014).Foi realizado contato telefônico com as colaboradoras, explicando os objetivos, procedimentos e aspectos éticos da pesquisa. Com a aceitação prévia foi marcado, conforme disponibilidade, um encontro com o objetivo de esclarecimento formal do estudo e assinatura do Termo de Consentimento Livre e Esclarecido (TCLE).

A coleta dos dados ocorreu no ano de 2018, me- diante entrevista fenomenológica aberta, individual, presencial e/ou online (via Skype ${ }^{\circledR}$ ). A modalidade da entrevista justifica-se pela escolha e disponibilidade da colaboradora, visando seu bem-estar. A pergunta-disparo foi: Como são suas experiências de relação dialógica na clínica gestáltica? As demais intervenções ocorreram mediante a interação pesquisador-colaborador, objetivando descrição e aprofundamento, seguindo os princípios fenomenológicos norteadores (Gomes, 1997; López, 2014). A duração média das entrevistas foi de trinta minutos. Os dados foram coletados via gravador em áudio MP3 e transcritos em sua totalidade no programa Microsoft Word $2010^{\circledR}$, sem correção, visando a fidedignidade das verbalizações.

\section{Análise dos Dados}

O método fenomenológico-semiótico pauta-se em uma tríade reflexiva, que permite análises progressivas e sistemáticas. Partindo desta perspectiva, a análise dos dados seguiu as etapas da reflexibilidade fenomenológica, que perpassa pela descrição, redução e interpretação (Gomes, 1997; Gomes, 1998; Gomes, 2007; Lanigan, 1997).

A descrição fenomenológica consiste na leitura e ordenação do material empírico, demarcando unidades de sentido que respondam à problematização e aos objetivos propostos. A redução fenomenológica indica os elementos invariantes das descrições, ou seja, temáticas comuns a todas as colaboradoras. A interpretação fenomenológica é a reflexão que permite o confronto das intencionalidades, criticando e propondo apontamentos pautados na literatura científica (Gomes, 1997; Gomes, 1998; Gomes, 2007; Lanigan, 1997).

As nomeações das unidades de sentido foram construídas baseadas em terminologias da área da fenomenologia, do existencialismo dialógico e da gestalt-terapia. Evidencia-se, portanto, a consciência do pesquisador sobre a análise dos dados, premissa básica dos estudos fenomenológicos.

\section{Resultados e Discussão}

A análise fenomenológica permitiu a extração de unidades variantes e invariantes, totalizando em onze significados. As variantes referem-se a significados não encontrados na fala de todas colaboradas, não sendo possível uma estrutura fenomênica comum. As invariantes dizem respeito a um mundo de significados partilhado entre todas as colaboradoras, refletindo um sentido intersubjetivo, enfoque deste estudo. As seteunidades de sentido variantes encontradas foram nomeadas como: relação dialógica percebida como movimento rítmico, enfoque na relação Eu-Tu em detrimento a Eu-Isso, percepção da necessidade de acolhimento, diferenciação entre $\mathrm{Eu}$ e o Outro, relação dialógica percebida como processo de vulnerabilidade, experiências positivas de investigação fenomenológica e relação dialógica percebida como elemento humanizador. Essas unidades serão 
apresentadas brevemente a seguir, com fins de descrição e não de discussão.

Helena e Sofia descrevem a relação dialógica como um movimento rítmico entre o Eu-Isso e o Eu-Tu. Em relação a isso, constatou-se um enfoque no Mundo do Tu em detrimento do Mundo do Isso por Glória e Isabel. A primeira descreve a relação Eu-Tu com palavras como "lindo", "pleno" e "sagrado", enquanto a segunda diz ser algo "mágico", "fluido" e "rico". Ambas verbalizaram pouco sobre o Eu-Isso. Portanto, evidencia-seum sentido valorativo que pode ferir os princípios dialógicos.

Para Isabel e Júlia, na relação dialógica é imprescindível que o psicoterapeuta acolha o cliente durante todo o processo terapêutico, como modo de contato seguro. Elas tambémentendem que a relação dialógica é humanizadora, pois se tornam mais sensíveis e humanas mediante o encontro com o outro. As unidades "percepção da necessidade de acolhimento" e "relação dialógica percebida como elemento humanizador"revelam um sentido não relacional, visto que há foco ora na figura do cliente quando falam do acolhimento, ora no terapeuta quando percebem a humanização de si mesmas, o que descaracteriza o entre como princípio exímio do dialógico.

Helena e Glória verbalizaram sobre a diferenciação Eu-Outro no contato terapeuta-cliente, afirmando a conservação do senso de self como elemento imprescindível na relação dialógica. Glória fala, também, das experiências positivas de investigação fenomenológica, assim como Sofia. Para elas, essa é uma ferramenta que permite o terapeuta compreender o cliente, constituindo-se como atitude Eu-Isso. No tocante à vulnerabilidade, Helena relata que a relação dialógica pressupõe a fragilidade do terapeuta ao se entregar ao entre.

As unidades de sentido de natureza invariante totalizaram quatro, sendo: experiências de abertura e presença, percepção da necessidade de epoché no atendimento, percepção das dificuldades no percurso clínico eexperiências positivasde atitude Eu-Tu.A seguir, estas unidades serão discutidas e refletidas fenomenologicamente.

\section{Experiências de abertura e presença}

Esta unidade de sentido diz respeito às experiências de estar inteiro ao cliente, uma postura gestáltica fundamental. Os excertos das entrevistas apresentados a seguir descrevem tal unidade.

"É estar entregue, é eu estar aqui, porque olha, tem dias que atendo oito pacientes, nove pacientes, desde manhã até à noite, sai um e entra outro. Cada um com uma coisa diferente, com um conflito diferente, com uma dor, com uma situação diferente. Ele saiu, dou dez minutinhos, dou aquela relaxada e tal, e tenho que estar pronta para o outro que vai vir com outra dor, com outro conflito. Aí aquele que foi, foi. Agora eu es- tou aqui para você, entendeu? Isso que é ter um vínculo, que é sentir. Aí sai outro, chega outro, aí é outro problema também, é outra situação, e eu tenho que estar inteira para ele, porque se eu não estiver inteira nessa relação, nesse momento, a terapia, da minha parte, o paciente sente. Ele sente quando você está para ele e quando você não está para ele”. (Isabel)

“Olha, é algo que a gente... é no entre mesmo, é aqui nesse momento, não dá pra... É uma coisa que você sente acolhida e confortada, e junto; 'tô aqui e vamos pra onde for e a terra não me importa'. Então não dá para 'Como é estar com o outro?'. É você conseguir alcançá-lo. Eu só estou te acompanhando para um determinado mundo que eu não sei onde vamos chegar”. (Júlia)

“(...) estar sempre muito mais disponível para se revelar porque eu estou muito mais terapeutizada e estou de fato disponível para isso, porque não é todo terapeuta que está disponível pra relação, porque isso não é ser gestalt-terapeuta, que tem esse lado da dialógica; isso é uma disponibilidade, é uma postura da pessoa, né?É uma postura na vida. Não é uma postura terapêutica, né?Então é uma postura de como estou na vida". (Sofia)

Helena fala da disposição para entrar na dança, que é a relação terapêutica. Para ela: "É um movimento que eu faço, que eu disponho a fazer, quando eu estou aprendendo a dançar (...) E aí, quando eu me ponho com essa disponibilidade, eu posso me confrontar com suas resistências". Isabel menciona um movimento de voltar-se para o outro, para o sofrimento do outro na sua totalidade. É olhar com os olhos e a alma, é escutar com os ouvidos e o coração. Essa postura dialógica é fundamental para que o cliente se sinta acolhido e amparado nas suas questões existenciais. Júlia expõe a abertura e a presença do terapeuta narrando como um ir com o cliente para onde ele quiser e puder ir, para uma terra desconhecida. Isso é estar com o outro, acompanhando seus desvelamentos.

Glória fala da abertura de ambos, psicoterapeuta e cliente. Para ela, não adianta o terapeuta estar disponível e aberto e o cliente, não. Isso remete à mutualidade da relação terapêutica.O trecho a seguir evidencia essa significação.

"Aberta no sentido de estar disponível a isso, e que o outro também está disponível para me permitir entrar, porque não adianta o terapeuta estar disposto, disponível e preparado pra esse encontro, se o paciente não consegue abrir espaço pra isso. (...) Porque a gente, através da dialógica, a pessoa vai trazendo, se expondo, às vezes pouco mais, outros pouco menos, aí 
é onde eu preciso investigar, né? Porque quem traz com mais fluidez é tranquilo, outros não”. (Glória)

$\mathrm{Na}$ relação dialógica, o terapeuta deve estar na atitude Eu-Tu, porém, sem exigir isso do cliente. Isso pressupõe aceitação da existência do cliente, do como ele consegue estar em relação (Hycner, 1995; Yontef e Bar-Yoseph, 2014). Assim, a resistência do cliente deve ser respeitada, não exigindo do cliente uma atitude de abertura, pois, como afirma Hycner (1995),"problemas 'só' são problemas quando olhamos para nossa existência objetivamente, ou seja, de maneira EU-ISSO” (p. 127). Deste modo, o autor fala da importância do problema e da sabedoria da resistência. A fala de Glória parece indicar que ela espera uma atitude de abertura por parte do cliente. Desta forma, sugere-se uma atitude de manipulação e de expectativa, característica do mundo Eu-Isso.

Sofia explana essa temática ao percebê-la para além do setting terapêutico. Para ela, abertura e presença é uma postura na vida, pois o consultório é a extensão do viver. Ela reitera: "essa postura não é uma postura no setting terapêutico, é uma postura que eu tenho buscado na vida. Então é como estar, é um estado de abrir o peito, de buscar minha alma, de conexão”.

Yontef e Bar-Yoseph (2014) descrevem que a postura do gestalt-terapeuta deve ser de interesse pelo cliente, em uma presença pessoal e transparente. Os autores enfatizam que, na abordagem dialógica, o psicoterapeuta trabalha para encontrar o outro, para compreendê-lo. Este encontrar o outro no seu mais secreto exige uma abertura e uma presença genuínas. Essa postura, para Luczinski e Ancona-Lopez (2010), pressupõe vulnerabilidade, pois há um revelar-se do terapeuta como ele é. A relação dialógica, portanto, é uma relação de vulnerabilidade, no sentido emque há exposição de sua alma para se alcançar a alma do outro.

A disponibilidade e a presença do terapeuta evidenciamuma entrega ao reino do entre, ao campo do intersubjetivo no contexto de psicoterapia. Isso implica em uma abertura amorosa para que o belo emerja, como diz Hycner (1995). Portanto, presença é abertura para o mundo fenomenológico do outro, é possibilidade de estar junto. Em Hycner e Jacobs (1997), a presença é compreendida como postura existencial, sendo um dos requisitos para a possibilidade de estabelecer diálogo. A presença como requisito para a relação dialógica também é confirmada em Yontef (1998) e Yontef (2002). Essa atitude é uma das características do relacionamento dialógico, uma forma de exploração da relação, um modo de estar com o outro. Já os momentos Eu-Tu, para Hycner e Jacobs (1997), são pontos culminantes do processo dialógico.

Essas preposições teóricas aludidas são encontradas emachados empíricos. Os resultados da pesquisa de Nascimento e Vale (2013) confirmam os da presente investigação, pois, em sua amostra de psicólogas, encontrou-se também a percepção da necessidade de disponibilidade para a realização do atendimento psicoterapêutico. Em Carvalho et al. (2015), obteve-se que a presença do psicoterapeuta enquanto sujeito ativo na relação faz parte do cuidado relacional com o cliente. Deste modo, a relação dialógica em gestalt-terapia implica que a pessoa do terapeuta esteja aberta para o encontro existencial e presente para o desvelar do entre.

Percepção da necessidade de epoché no atendimento Para Husserl (1907/1986), a fenomenologia institui-se como método e atitude. Holanda (1997) e Holanda (2009) a definem como uma filosofia, método, epistemologia e ciência. Sendo assim, enquanto psicoterapia fenomenológica, a gestalt-terapia utiliza da epoché como metodologia de acesso às vivências do cliente.Portanto, a utilização deste recurso possibilita a instrumentalização para o manejo da situação clínica. A necessidadede epochémanifestou-se nas entrevistas, apontada como de extrema importância para a relação terapêutica.

Glória relata que, ao praticar a redução fenomenológica, é possível entrar no mundo do outro, que é sagrado. Deste modo, é possível realizar a inclusão, uma das características do diálogo, em que o terapeuta busca experienciar o mundo do cliente (Hycner, 1995; Yontef, 1998; Yontef, 2002; Yontef \& Bar-Yoseph, 2014). Ela afirma:

"Isso que eu disse de entrar neste campo, neste lugar sagrado e conseguir experimentar essas coisas sem os meus conceitos, sem os meus... sem estar vestida de mim, e conseguir ver como o outro, ver e conseguir experimentar como o outro experimenta aquelas sensações, aquelas emoções, daquele campo”. (Glória)

Para Júlia e Isabel, a utilização da epoché é uma função básica na prática do psicoterapeuta de orientação gestáltica, fundamentando-se como premissa essencial no atendimento clínico. Júlia declara: "Uai, é minha função estar aí, tentando alcançá-lo, me pondo entre parênteses, tentando tirar julgamentos e preconceitos, tentando entender o funcionamento dele enquanto pessoa". Isabel corrobora com o pressuposto e reitera:

"Naturalmente, porque o meu papel aqui é o paciente, é a pessoa em si. É onde a gente... é a gente tipo se despir de todos os valores e crenças, porque isso é ser terapeuta. Não estamos aqui para olhar isso ou aquilo (...). Você tem que se despir de tudo, de valores, de crenças, de religião. Isso é ser um bom terapeuta, também. Não misturar aquilo que é seu daquilo que é do paciente”. (Isabel) 
Para Helena, a suspensão fenomenológica revela-se na relação com o outro, de um eu e um não-eu. Ela traz o conceito de fronteira de contato para se referir que ao estar com o outro é necessário suspender suas crenças e valores, para que se possa ver o outro como ele é. Ao mesmo tempo, faz-se necessário estar consigo mesmo, awareness de si na relação. E por fim, descreve a relação terapêutica como um movimento, um trabalho de artista.Assim, tem-se que a epoché se dá na relação, como uma tentativa e não como um estado permanente. É nas pinceladas que elasurge, no campo do entre. Ainda para Helena:

"E embora quando eu estou atendendo, não é de mim que estou falando, mas eu estou aqui, né? Eu sou Helena, eu sou Helena em qualquer momento. É claro que eu tenho que suspender certas coisas, mas eu sou Helena. Então é de novo uma dança entre a sua fronteira e a minha fronteira, respeitando o outro, mas me respeitando. Então é um trabalho de pinceladas, bem artístico mesmo". (Helena)

A atitude do gestalt-terapeuta é essencialmente fenomenológica, em um movimento transcendente de busca do outro em sua totalidade. Sofia refere-se a epochéno atendimento clínico como um modo suportivo de estar na relação dialógica e como uma fenomenologia pura. A seguir, será descritaessa percepção.

“Então, esse suporte é no sentido, assim... eu não te julgo, entende? O suporte é uma palavra que talvez para além de aceitação, o suporte para mim é a fenomenologia pura. Para mim, suporte, porque nem sei se outra palavra é meIhor, mas talvez seja ela, é no sentido de que eu estou com você e eu estou com você, entende? No sentido de que não há julgamento, eu simplesmente te vejo, entende? Eu simplesmente te enxergo, eu simplesmente me coloco diante de você. É por aí, é de verdade tentar olhar o mais fenomenológico, ser o mais fenomenológico possível, ser mais fenomenólogo possível, mais puro de verdade. Eu sou esse humano e estou aqui com outro humano. É só isso, sem julgamentos”.(Sofia)

Esses excertos referem-se à atitude fenomenológica em psicoterapia. Ribeiro (2012) aponta a fenomenologia enquanto metodologia que ajuda o psicoterapeuta a ler, descrever e interpretar os fenômenos emergentes na situação clínica, sendo a redução fenomenológica um modo de colocar o ser no mundo em evidência. Já Cardella (2017) reitera que a atitude fenomenológica-existencial ajuda o profissional a clarear os significados que o cliente atribui, por meio da descrição da experiência, bem como pela observação do como ela ocorre. Assim, para Ribeiro (1994):
Trabalhar fenomenologicamente é tentar ficar com a realidade como é em si, é trabalhar a partir dela. É ver o fenômeno como a realidade primeira e a partir dele e só dele caminhar para a compreensão do que significa ir além do fenômeno(p. 15).

Esta postura fenomenológica foi encontrada nos resultados de Nascimento e Vale (2013), em que as colaboradoras perceberam a relevância da suspensãofenomenológica para a condução clínica em gestalt-terapia. Em Carvalho et al. (2015) tem-se resultados semelhantes. Os autores evidenciam a necessidade de suspender os a prioris e as questões pessoais para a realização de uma escuta especializada. Deste modo, a relação dialógica em gestalt-terapia pressupõe o uso de époché, pois, como afirma Hycner (1995), o terapeuta deve entrar no mundo subjetivo do cliente suspendendo seus pressupostos.

\section{Percepção das dificuldades no percurso clínico}

Para as colaboradoras, a clínica é um espaço permeado por dificuldades. Sofia relata que a prática em gestalt-terapia exige de si um trabalho interno profundo, uma busca por autoconhecimento e por autossuporte. Helena metaforicamente retoma o trabalho clínico como o de artista, no qual as pinceladas perpassam por um movimento atento e árduo. Ela também descreve a relação terapêutica como uma luta, ao se referir aos percalços encontrados no caminho clínico.

Júlia menciona a dificuldade de estar presente o tempo todo na sessão, bem como do uso de técnicas que, para o gestalt-terapeuta, não têm a função de resolução imediata, que é uma busca desenfreada na sociedade contemporânea. Glória também fala da árdua tarefa de abrir mão de si mesma, como bem apontou Sofia. Ela menciona que não é fácil suspender suas questões pessoais e abrir-se inteiramente para o cliente. Portanto, a relação revela-se como um processo de ir e vir.

"Então, assim, exige muito da gente, exige muita... Eu tenho que abrir muito ego, tenho que abrir mão do meu ego, me desapegar do meu ego porque senão eu não consigo estar lá, entende? (...) Eu sempre achei que a prática clínica por muito tempo era opção, hoje eu acho que é mais expiação, porque é 'troço' que exige muito, exige muito, principalmente o ego”. (Sofia)

"E é aí que você vai dando suas pinceladas, porque lidar com a fronteira do outro, com a resistência do outro, exige um trabalho árduo (...). Não é fácil, como eu falei, é uma dança, e às vezes é uma luta. Não é só uma dança, porque a dança fica muito romântico, às vezes é também uma luta. É bem por aî". (Helena) 
"Não é fácil, não é fácil (...). Então, cuidado, essa presença é muito complicado. Às vezes você está ali conversando com ele e dá uma voada, dá, até você retomar e estar ali com a pessoa, não é algo... Gestalt-terapeuta é uma situação muito difícil, porque os outros têm técnicas, e você vai ali para resolver e pronto e acabou". (Júlia)

Porque a gente abrir mão de nós mesmos, dos nossos conceitos, das nossas coisas, não é uma coisa fácil, é exercício. E aí conseguir isso, abrir mão de mim, das minhas coisas e ainda conseguir um espaço aberto do outro para que eu possa entrar não é toda hora. Por isso que às vezes acontece”. (Glória)

Isabel aponta os questionamentos internos que resultam em crise existencial, do repensar a pessoa do terapeuta. Ela declara: “(...) porque muitas vezes no início você fala, você pensa assim, você dá uma crise existencial mesmo. Eu estou sendo um bom terapeuta? Será que eu estou fazendo terapia? É onde que você começa a se cobrar".

Estes excertos descrevem o setting terapêutico como um campo de dificuldades. A clínica revela-se como um espaço permeado por percalços, por exigências que evocam no terapeuta dialógico uma postura de busca de autossuporte, autoconhecimento, habilidades e awareness de si na relação. A psicoterapia é, por excelência, uma arte e uma ciência árdua. Ao dissertar sobre a relação dialógica, Joyce e Sills (2016) afirmam:

um terapeuta que oferece uma relação dialógica precisa estar completamente presente, compreendendo, validando e sendo autêntico com seu cliente. Isso é, certamente, uma prática muito exigente e difícil, à qual aspiramos e não constantemente alcançamos. No entanto, é a intenção que é mais importante (p.70).

Portanto, o essencial é a intencionalidade de estar com o outro em uma postura dialógica, o que nem sempre é possível. Isso denota a humanidade do terapeuta, que deve ser olhada de forma sagrada e não negada. Joyce e Sills (2016) afirmam que muitos terapeutas não conseguem ficar presentes ou inclusos por longos períodos durante a sessão psicoterápica, confirmando os achados deste estudo.

Buber (1942/1963) utiliza a metáfora da vereda estreita para descrever as questões humanas como incertezas, paradoxos e inseguranças frente ao oculto. Hycner e Jacobs (1997) corroboram esta metáfora ao afirmarem que, em psicoterapia dialógica, o terapeuta caminha em vereda estreita, pois não há segurança; é sempre um caminho para o desconhecido. Sendo assim, o percurso clínico dá-se por meio de dificuldades no caminho. Em seu âmago, remete à natureza própria da psicoterapia, que é processo aqui-agora, mistério puro.
Destas dificuldades no caminhar do clínico, surge a necessidade de psicoterapia pessoal e de supervisão. Essas modalidades são recursos a que o terapeuta pode recorrer para que possa ser assistido em seus processos pessoais e profissionais. Portanto, trata-se de reconhecer nossas vulnerabilidades, nossa mais profunda humanidade.Assim, a relação dialógica mostra-se como um encontro de humanidades, que mobiliza os pares. Tudo o que ocorre no consultório diz respeito ao campo do entre, como Hycner (1995) reitera:"É o entre que precisa ser reconhecido" (p. 39). Reconhecer a esfera do entre possibilitaa relação genuína. Afinal, o terapeuta deve estar a serviço do dialógico (Hycner \& Jacobs, 1997).

Experiências positivas de atitude Eu-Tu.

A investigação fenomenológica possibilitou a emersão de verbalizações sobre as experiências positivas de atitude Eu-Tu na clínica gestáltica. Helena refere ao dialógico como uma das coisas mais bonitas e profundas que se pode ocorrer em psicoterapia. Para ela: “(...) vivenciar o dialógico é uma das coisas mais difíceis, mas é também uma das coisas mais profundas e bonitas que acontece na terapia”. A seguir, serão realizadas outras descrições fenomenológicas sobre essa unidade de sentido.

"Então, é um momento tão singular que eu não sei se eu consigo expressar, porque eu estou... sou eu andando em uma terra muito sagrada, do outro. Eu estou ali passeando em uma coisa do outro, que muitas vezes... que nem ele se permite passear naquele lugar. Então é muito... é mágico assim, eu não tenho muito... eu não tenho como te descrever a sensação disto. É a sensação de fato de estar num lugar sagrado, onde eu reverencio a dor do outro, o sofrimento do outro". (Glória)

“(...) e em determinados momentos de fato a postura Eu-Tu, de interesse, de disponibilidade, de ser suportivo, de ter lealdade, de ter disponibilidade para o outro, em dado momento é como se minha alma falasse com a alma do outro. Então é como se eu desse espaço - como se fosse não, eu dou espaço para minha alma e, consequentemente, a alma do outro também aparece". (Sofia)

“(...) e quando o encontro se dá é algo... é fantástico. Eu me modifico, você se modifica. Aí é que está, a gente é terapeuta pra se curar mesmo, porque nesse encontro a gente sai fortalecido o tempo inteiro”. (Júlia)

Essasdescrições parecem refletiro Eu-Tu buberiano. Deste modo, as verbalizações sugerem que a atitude dialógica do terapeuta propicia os momentos Eu-Tu, bem como a abertura do cliente para tal 
fenômeno. Para Hycner (1995), a relação Eu-Tu é o reconhecimento do outro em sua alteridade, configurando-se como um encontro verdadeiro.O Mundo do Tu apresenta-se como presença genuína, como um estar-aí-com-o-outro, é uma atuação com todo o Ser. Segundo Fernandes (2007),“Onde, pois, o humano se abre para o mundo do Tu, ali ele encontra não mais a fatalidade, mas sim a liberdade e a graça, isto é, gratuidade e graciosidade do encontro" (p. 205). Deste modo, entende-se a relação Eu-Tu como encontro de humano para humano, como bem descreve Sofia: " $E$ nesse momento, é o momento que a gente cria uma afinidade, uma coisa, uma cumplicidade, uma aproximação, porque aí de fato é de pessoa a pessoa".

A relação Eu-Tu é um encontro de alma para alma, como percebe Sofia, confirmado pelas acepções de Hycner (1995) ao enunciar o momento Eu-Tu como um olhar para o outro como pessoa. Neste momento:

Eu olho para dentro do outro e ele olha para dentro de mim. Algo acontece no entre. Há um momento de encontro. Cada um de nós é tocado por algo além do nosso self- por essa outra pessoa. É simultaneamente um momento de união e de separação. Depois, nenhum de nós é exatamente o mesmo que éramos momentos antes. Nosso encontro é "algo maior" que a soma total do que trouxemos separadamente para esta situação. (Hycner \& Jacobs, 1997, p. 100)

Uma característica do momento Eu-Tu é sua imediaticidade, pois, como afirma Buber (1923/2001): "O Tu encontra-se comigo por graça; não é através de uma procura que é encontrado" (p. 12). Destarte, momento Eu-Tu na clínica gestáltica é momento de graça, que nos leva ao encontro do sagrado no aqui-agora, pois se constitui na esfera do espiritual, mobilizando a existência como um todo (Hycner, 1995; Vaz, 2007). Essas preposições teóricas confirmam a fala de Glória que diz que o momento Eu-Tu na clínica é sagrado, bem como a de Helena, que fala do amor terapêutico como algo espiritual. Para ela:

"É um amor diferente, o amor pelo cliente é um desejo de ir com ele onde ele for e estar ali para ajudar, para explorar aquela dor(...) Mas por amor pelo seu cliente, pelo seu paciente, é uma coisa, é espiritual, é espiritual”.

Cardella (1994) assevera que a psicoterapia é uma prática do amor, em que na relação Eu-Tu a amorosidade é compartilhada no entre. A autora apresenta o amor terapêutico e o exercício da psicoterapia na busca da relação dialógica como domínio do espiritual. Mundo do Eu-Tu, portanto, é o mundo da espiritualidade.

Na contemporaneidade percebe-se uma carência na vida dialógica, em que há dificuldades de estabelecer contatos plenos. Deste modo, a psicoterapia gestáltica configura-se como dispositivo que possibi- lita encontros genuínos, um viver dialógico. Afinal, Buber (1923/2001) proclama: "Toda vida atual é encontro" (p. 13).Em Buber (1930/2014) tem-se a acepção de que, na vida dialógica, há um fazer verdadeiro. Isso quer dizer que todo o viver genuíno se encontra no campo do encontro entre humanidades. Em vista disso, a gestalt-terapia é convocada a ser a clínica da restauração de contatos, da consumação de humanidades na relação Eu-Tu.

Isabel também relata suas experiências positivas de atitude Eu-Tu. Ao ser indagada sobre os momentos Eu-Tu na clínica gestáltica, Isabel traz em suas verbalizações o conceito de atitude Eu-Tu. Em relação a isso ela afirma: "É ser humano, é ser gestalt (risos). Porque gestalt é isso, é você ser humano, é você ser, sabe, essa coisa gostosa mesmo do humanismo, do existencialismo, do acolhimento, do aqui-agora, 'eu estou aqui pra você', essa relação Eu-Tu”. Ela continua: “Aí, para mim é perfeito, sabe, eu acho que eu não seria uma boa terapeuta se eu não pudesse sentir, se eu não pudesse ter esse vínculo, essa relação mesmo, essa relação dialógica”. Na fala de Isabel percebe-se uma confusão em relação às questões teóricas, denotando dificuldades de diferenciação entre os conceitos de atitude Eu-Tu e de momento Eu- Tu.

A colaboradora se refere a uma atitude quando reitera a postura de acolhimento e abertura do terapeuta para com o cliente. Essas são características da atitude Eu-Tu e não do momento em si. A atitude Eu-Tu refere-se também a uma postura do terapeuta de abertura e de entrega ao entre, enquanto que o momento Eu-Tu é um instante de graça, de encontro genuíno entre humanidades (Hycner, 1995; Yontef \& Bar-Yoseph, 2014; Yontef, 1998; Yontef, 2002).

Deste modo, percebe-se a confusão teórica da colaboradora, o que pode ter efeitos técnicos na praxe clínica. Por isso, se faz necessário que a formação do gestalt-terapeuta contemple embasamento teórico-filosófico consistente, a considerar sua utilidade técnica na situação clínica. Outro ponto a ser considerado é a formação continuada em gestalt-terapia, tão importante como a formação inicial, a considerar seu caráter de aprofundamento teórico e técnico, possibilitando uma prática gestáltica com excelência.

\section{Considerações Finais}

A gestalt-terapia constitui-se como uma clínica do encontro, do entre. Isto significa que o percurso clínico se instaura no campo da intersubjetividade, dimensão em que se emergem as centelhas do sagrado, que é o encontro humano. Essa abordagem que privilegia o contato genuíno revela-se como possibilidade de restauração para uma sociedade em que há falência do verdadeiro viver, que para Buber é encontro. Considerando as premissas do existencialismo dialógico, buscou-se compreender a interface com o campo da psicoterapia gestáltica. Para isso, recorreu-se ao mundo do vivido de psicólogas gestaltistas, visando colher vislumbres da relação dialógica. 
Ressalta-se que a pesquisa se funda em uma compreensão parcial, pois considera-se o espaço da clínica, e logo do encontro inter-humano, como mistério. Assim, a relação dialógica em gestalt-terapia não é passível de descrição fiel, a considerar sua dimensão inexprimível. Trata-se, portanto, de impressões do vivido do encontro humano, de indicativos da relação terapêutica. Deste modo, nos resta o caráter inacabado da gestalt, que é própria do viver humano.

Foram encontradas onze unidades de sentido, sendo que sete são de natureza variante.As percepções dos pesquisadores evidenciaram uma unidade em que algumas colaboradoras parecem valorizar o Mundo Eu-Tu em detrimento do Mundo Eu-Isso. Neste sentido, temos uma problemática em relação ao conhecimento teórico das entrevistadas que pode influenciar na praxe, visto que o cliente não precisa necessariamente estar em atitude Eu-Tu. Ele, por exemplo, pode ter alta psicoterápica sem experimentar os momentos Eu-Tu, o que não significa insucesso do trabalho clínico. Assim sendo, esse dado remete a uma atitude contrária aos postulados teórico-filosóficos da abordagem dialógica em gestalt-terapia.

A relação dialógica também foi entendida como uma forma de acolhimento e humanização por parte do terapeuta, evidenciando um sentido não relacional, ao enfocar ora a figura do terapeuta, ora a figura do cliente. Esse dado merece atenção, visto que descaracteriza a base da psicoterapia dialógica, que se assenta na noção de entre.A diferenciação entre o eu e o não-eu foi reiterada por algumas colaboradoras como sendo necessária para a relação terapêutica. As experiências positivas de investigação fenomenológica foram relatadas como atitudes Eu-Isso, bem como houve percepções da relação dialógica como um processo de vulnerabilidade.

Todavia, o estudo pautou-se na apreensão de significados no campo da intersubjetividade das colaboradoras, ou seja, de experiências comuns entre as gestalt-terapeutas. Destaca-se a importância destes elementos invariantes na pesquisa fenomenológica, visto que se refere à busca de universalidades no que compete às essências das experiências humanas. Não se trata de desconsiderar as singularidades dos indivíduos, que são fundamentais na descrição do campo da subjetividade. Porém, como recorte, delimitou-se os aspectos intersubjetivos das experiênciasnas reflexões fenomenológicas.

Os resultados sugerem que a relação dialógica, para as colaboradoras, se funda nas experiências de aberturae de presença.É importante salientar que o cliente também deve estar aberto e disponível para que o encontro ocorra, porém, o terapeuta não deve exigir ou esperar tal atitude. Essa postura compete ao terapeuta e não ao cliente. Deve-se, portanto, aceitar o modo como o cliente está em psicoterapia. Nos achados desta pesquisa, percebe-se a expectativa em relação à abertura do cliente, evidenciando uma atitude Eu-Isso.
Portanto,éa atitude dialógica do terapeuta que permite que ele encontre o cliente, caso este esteja disponível. Este encontrar o outro na sua alteridade pressupõe o uso de epoché para que se acesse o cliente-fenômeno tal como é. Daí decorre um andar em solo sagrado, um percorrer no mundo fenomenológico do cliente. Esse percurso clínico é constituído de dificuldades, de um trabalho que exige autossuporte, autoconhecimento, habilidades e awareness de si na relação.

Foram encontradas também as experiências positivas de atitude Eu-Tu, que, para algumas colaboradoras, anunciam a presença dos momentos Eu-Tu. Para uma colaboradora, houve uma confusão na diferenciação entre os conceitos de atitude e momentos Eu-Tu.

Alguns achados evidenciam a necessidade de uma formação sólida e consistente do ponto de vista da inter-relação entre aspectos teórico-filosóficos e práticos-técnicos da clínica gestáltica. Para além da formação inicial, deve-se refletir sobre a importância da formação continuada em gestalt-terapia, como dispositivo pedagógico que propicie expansão dos conhecimentos teóricos, refletindo em uma prática clínica qualificada.

Deste modo, a relação dialógica em gestalt-terapia revela-se como um campo de pluralidades. $\mathrm{O}$ encontro terapêutico é dança, luta, trabalho artístico,sacralidade, profanidade. Nessa pluralidade fenomênica constitui-se o labor do terapeuta, profissional que lida com as contradições da existência humana. À guisa de conclusão, já que o caráter conclusivo nos remete a algo acabado, temos que a relação dialógica no campo da psicoterapia gestáltica mostra-se como uma gestalt inacabada, como um processo, um ir e vir.

Trata-se de um trabalho artístico que exige do artista-terapeuta pinceladas misteriosas. Essas pinceladas requerem da pessoa do terapeuta uma atitude cuidadosa e atenta para as infinitas possibilidades que podem emergir no contexto psicoterapêutico. $\mathrm{O}$ cliente constitui-se também como artista, autor das suas histórias e expositor de suas fragilidades e de sua humanidade. Portanto, é no encontro entre o artista-terapeuta e o artista-cliente que se dão os mistérios da relação dialógica.

Pelo caráter inacabado da presente análise fenomenológica, sugere-se novas pesquisas sobre a temática. Estudos futuros podem investigar a inter-relação entre espiritualidade e o encontro Eu-Tu na clínica gestáltica, bem como as experiências dos clientes no que se refere ao dialógico. Devido a alguns dados encontrados, tanto em unidades variantes quanto em invariantes, recomenda-se pesquisas que avaliem a adesão dos terapeutas aos princípios dialógicos, evidenciando a intersecção entre teoria e prática.

Espera-se que os vislumbres refletidos nos resultados possam contribuir para as discussões acadêmicas na comunidade gestáltica brasileira, promovendo 
debates acerca dos princípios dialógicos na aplicabilidade clínica e a qualidade da formação do gestalt-terapeuta brasileiro. Almeja-se, também, que os dados possam colaborar nas reflexões dos clínicos em seu trabalho psicoterapêutico.

\section{Referências}

Amatuzzi, M. M. (2009). Psicologia Fenomenológica: Uma aproximação teórica humanista. Estudos de Psicologia, 26(1), 93-100.

Andrade, C. C. \& Holanda, A. F. (2010). Apontamentos sobre pesquisa qualitativa e pesquisa empírico-fenomenológica. Estudos de Psicologia, 27(2), 259-268.

Buber, M. (1963). ¿Qué es el hombre?México: Fondo de Cultura Económica.

Buber, M. (2001). Eu e Tu.(N. A. V. Zuben, Trad.)São Paulo: Centauro (Originalmente publicado em 1923).

Buber, M. (2014). Do diálogo e do dialógico. (M. E. de S. Queiroz \& R. Weinberg, Trad.) São Paulo: Perspectiva (Originalmente publicado em 1930).

Cardella, B. H. P. (1994). O amor na relação terapêutica: Uma visão gestáltica. São Paulo: Summus.

Cardella, B. H. P. (2017). A construção do psicoterapeuta: Uma abordagem gestáltica. São Paulo: Summus.

Carvalho, L. B., Alves, A. M. F., Passos, C. A., Lopes, F. G., Holanda, R. B. \& Moreira, V. (2015). A ética do cuidado e o encontro com o outro no contexto de uma clínica-escola em Fortaleza. Revista da Abordagem Gestáltica, 21(1), 1-12.

Conselho Nacional de Saúde. Resolução n $\mathrm{n}^{\mathrm{O}} 466$, de 12 de dezembro de 2012, Diário Oficial da União 59 (2012)

Conselho Nacional de Saúde. Resolução n ${ }^{\circ} 510$, de 7 de abril de 2016, Diário Oficial da União 44-46 (2016).

Fernandes, M. A. (2007). 'O que significa dizer tu?'Meditação acerca das palavras fundamentais 'Eu-Tu" e 'Eu-Isso". Revista da Abordagem Gestáltica, 13(2), 195-205.

Figueiredo, L. C. (1993). Sob o signo da multiplicidade. Cadernos de Subjetividade, 1(1), 89-95.

Garnica, A. V. M. (1997). Algumas notas sobre pesquisa qualitativa e fenomenologia. InterfaceComunicação, Saúde, Educação, 1(1), 109-122.
Gil, A. C. (2017). Como elaborar projetos de pesquisa. São Paulo: Atlas.

Gold, E. \& Zahm, S. (2014). A necessidade de pesquisa em gestalt-terapia. Em P. Brownell (Org.), Manual de teoria, pesquisa e prática em gestalt-terapia (pp. 43-54). Petrópolis: Vozes.

Gomes, W. B. (1997). A entrevista fenomenológica e o estudo da experiência consciente. Psicologia USP, 8(2), 305-336.

Gomes, W. B. (Org.). (1998). Fenomenologia e pesquisa em psicologia. Porto Alegre: Editora da Universidade Federal do Rio Grande do Sul.

Gomes, W. B. (2007). Distinção entre procedimento técnico e lógico na análise fenomenológica. Revista da Abordagem Gestáltica, 13(2), 228-240.

Hycner, R. (1995). De pessoa a pessoa: Psicoterapia dialógica. São Paulo: Summus.

Hycner, R. \& Jacobs, L. (1997). Relação e cura em gestalt-terapia. São Paulo: Summus.

Holanda, A. (1997). Fenomenologia, psicoterapia e psicologia humanista. Estudos de Psicologia, 14(2), 33-46.

Holanda, A. (2009). Fenomenologia e psicologia: Diálogos e interlocuções. Revista da Abordagem Gestáltica, 15(2), 87-92.

Holanda, A. (2011). Pesquisa fenomenológica e psicologia eidética: Elementos para um entendimento metodológico. Em M. A. T. Bruns\& A. F. Holanda (Orgs.). Psicologia e fenomenologia: Reflexões e perspectivas ( $2^{\circ}$ ed.). (pp.41-64 ). Campinas: Alínea.

Husserl, E. (1986). A ideia da fenomenologia. (A. Mourão, Trad.) Lisboa: Edições 70 (Originalmente publicado em 1907).

Joyce, P. \& Sills, C. (2016). Técnicas em gestalt: Aconselhamento e psicoterapia. Petrópolis: Vozes.

Lanigan, R. (1997). Capta versus data: Método e evidência em comunicologia. Psicologia: Reflexão e Crítica, 10, 17-45.

López, S. M. (2014). La entrevista fenomenológica: Una propuesta para la investigación en psicología y psicoterapia. Revista da Abordagem Gestáltica, 20(1), 71-76.

Luczinski, G. F. \& Ancona-Lopez, M. (2010). A psicologia fenomenológica e a filosofia de Buber: O encontro na clínica. Estudos de Psicologia, 27(1), 75-82. 
Nascimento, L. C. S. \& Vale, K. S. (2013). Reflexões acerca do fazer ético na clínica gestáltica: Um estudo exploratório. Revista da Abordagem Gestáltica, 19(2), 157-166.

Ramon, S. P. (2010). A psicoterapia dialógica de Martin Buber. Psico, 41(4), 534-541.

Ribeiro, J. P. (1994). Gestalt-terapia- o processo grupal: Uma abordagem fenomenológica, da teoria do campo e holística. São Paulo: Summus.

Ribeiro, J. P. (2012). Gestalt-terapia: Refazendo um caminho. São Paulo: Summus.

Schaurich, D., Crossetti, M. G. O. \& Padoin, S. M. M. (2011). Filosofia buberiana e a produção da pós-graduação stricto sensu brasileira: Revisão integrativa. Revista Brasileira de Enfermagem, 64(6), 1132-1140.

Vaz, C. M. (2007). A gestalt-terapia e a questão do sagrado. Revista IGT na Rede, 4(7), 121-127.

Vinuto, J. (2014). A amostragem em bola de neve na pesquisa qualitativa: Um debate em aberto. Temáticas, 22(44), 203-220.

Yontef, G. (2002). The relational attitude in gestalt therapy theory and practice. International Gestalt Journal, 25(1), 15-34.

Yontef, G. \& Bar-Yoseph, T. L. (2014). Relação dialógica. Em P. Brownell (Org.), Manual de teoria, pesquisa e prática em gestalt-terapia (pp. 225241). Petrópolis: Vozes.

Yontef, G. M. (1998). Processo, diálogo e awareness: Ensaios em gestalt-terapia. São Paulo: Summus.

Zuben, N. A. V. (1979). Eclipse do humano e a força da palavra: Martin Buber e a questão antropológica. Reflexão, 4(13), 108-130.

Zuben, N. A. V. (2003). Martin Buber: Cumplicidade e diálogo. Bauru: Edux.

Zuben, N. A. V. (2008). A questão do inter-humano: Uma releitura de Eu e Tu de Martin Buber. Síntese: Revista de Filosofia, 35(111), 87-110.

Hinayana Leão Motta (Orcid). Possui graduação em Psicologia pela Universidade Católica de Goiás (1994), formação em Gestalt Terapia pelo Instituto de treinamento e Pesquisa em Gestalt Terapia de Goiânia e mestrado em Psicologia pela Universidade Católica de Goiás (2005). Professora adjunta da Faculdade de Psicologia da Universidade de Rio Verde (UniRV). Email: hinayanam@gmail.com
Gustavo Alves Pereira de Assis (orcid)1 - Graduado em Psicologia pela Universidade de Rio Verde (UniRV). Atualmente é residente em Infectologia pela Secretaria de Estado da Saúde de Goiás (SESGO) no Hospital Estadual de Doenças Tropicais (HDT) de Goiânia. Foi aluno de iniciação científica pelo Programa Institucional Voluntário de Iniciação Científica (PIVIC, 2017/2018 e 2018/2019). Email: gustavo15assis@gmail.com

Leila Ribeiro Satelis (orcid). Graduada em Psicologia pela Universidade de Rio Verde (UniRV) e especializanda em gestalt-terapia pelo Instituto de Treinamento e Pesquisa em Gestalt-terapia de Goiânia (ITGT). Foi aluna de iniciação científica pelo Programa Institucional Voluntário de Iniciação Científica (PIVIC, 2017/2018) com a linha de pesquisa sobre relação dialógica na clínica gestáltica. EMail: leilocasatelis5@gmail.com

Recebido em 15.12.2018

Aceito em 15.12.2019 